way. (For instance, the importance of specimen handling is emphasised but exact descriptions of smear preparation are not provided.) The final three chapters deal with principles of safe practice, including the role of clinical cytology in patient management, medicolegal considerations, and the contentious issue of the relative merits of fine needle aspiration and core biopsy. The intervening chapters are about specific areas of concern in practice, such as cystic lesions, lymphoid infiltrates and small round cell tumors.

It should be apparent that I like this book very much, and it does succeed in its purpose of restating the potential and problems of clinical cytopathology in a way that provides both orientation for the neophyte and advice for the practicing pathologist. Having said that, there are occasional jarring things about it. An inexplicable number of spelling errors are present, including one on the first page! A few sub-standard photomicrographs appear to have been gleaned from other sources, and other photomicrographs seem to be a "poor fit" with the findings described in the text.

But these are minor considerations. I intend to have trainees in my institution read the first few chapters several times during their time with the cytology service, and would certainly highly recommend this book to all practicing pathologists having any involvement with cytopathology.

William R Geddie

\section{Gram-positive pathogens}

Vincent Fischetti, Richard Novick, Joseph Ferretti, Daniel Portnoy, Julian Rood, Metals Park: ASM Press, 2006, pp 888, \$179-95 (hardcover). . ISBN 1555813437 , 2nd edition

When the journal solicits a book review from you, the e-mail contains the phrase, "as a result of your familiarity with the subject your name has been proposed as a potential author of a review". To be honest, it was because of my unfamiliarity with the subject matter of this book that I agreed to do it. I have a background in research involving Gram-negative pathogens, so I though it would be nice for a change to learn something about the other half of the bacterial world. The book also looks very impressive lying on the desk in my office. I leave it lying on the desk as a test. Due to lack of space in my department, my office is used a thoroughfare by assorted consultant microbiologists, biomedical scientists, trainees, administrators, infection control nurses, students and cleaners. I have noticed that many of them stop as they pass my desk when their eyes are drawn to the bright yellow book with the title in large black prin "Gram-positive pathogens". They usually comment that the book looks really interest ing and would like to borrow it after I have finished reviewing it. All of them ignore the rather battered dull blue volume containing my doctoral thesis on virulence factors in uropathogenic Escherichia coli (a Gram-negative bacterium, are you surprised?). I think on the whole this is a pretty good test. "But you can't judge a book by its cover!" I hear you all cry. Well in this case perhaps you can. This is the second edition of a previously successful book and, as you would expect in a publication from the American Society for Microbiology (ASM), all of the authors are leaders in their particular area of interest. It has been edited well, though there is some repetition in the section on antibiotic resistance mechanisms and a shor chapter in the staphylococcal section describing resistance in that species. For some species there are good details of clinical features of infection-for example, listeriosis and there is also a short chapter on pneumococcal vaccines, but for the majority of the pathogens, the sections concentrate on structure, genetics and pathogenesis. There are many good illustrations and several colour prints. The ASM says that this book will appeal to clinicians, infectious diseas specialists and instructors and students seeking a single reference source on Grampositive bacteria. At \$179.95, this is an expensive book and probably not suitable for the everyday diagnostic microbiologist (like me). I would also argue that there is not enough clinical information in the book for it to be really useful at the bedside for clinicians including infectious diseases' specialists. However, for those with a special interest in the biology of Gram-positive bacteria, in particular those researchers working in the field of bacterial pathogenesis, it is highly recommended. And, finally, what about the other people who eye up the book on my desk as they breeze through my corridor-office? Perhaps in the future, if I get the chance to review the third edition, I will let you know how many of them actually read it.

Peter A Riley

\section{CALENDAR OF EVENTS}

\section{Diagnostic histopathology of breast disease}

14-17 May 2007, Hammersmith Hospital (Imperial College), London.

A 4-day course on the Hammersmith Campus designed for pathologists at Consultant and Senior Trainee level and suitable for the final examination for MRCPath. The course will provide a comprehensive coverage of the histopathology of breast disease, with special emphasis on areas which pose diagnostic difficulties. The course is based historically on the extensive referral collection of Professor JG Azzopardi, to which has been added new cases from Charing Cross, Nottingham City and Addenbrooke's Hospitals. The course will be slanted towards practical diagnostic pathology with a specific session dealing with problems encountered in core biopsies and a special workshop dealing with the interpretation of HER2 immunostaining. The participants will be given ample time to study histological preparations, followed by illustrated discussions of the cases. In addition, there will be several daily talks on specific topics, given by eminent breast pathologists and followed by discussions. The topics will include: new issues in the interpretation of breast biopsies, breast immunohistochemistry, problematic breast lesions, dealing with the gross specimen, fibroepithelial, spindle cell and papillary lesions, proliferative lesions/carcinoma in-situ, sentinel lymph node biopsy and the impact of molecular genetics on diagnostic breast pathology. The faculty will include Anthony Douglas-Jones, Ian Ellis, Bharat Jassani, Andrew Lee, Sarah Pinder, Jorge Reis-Filho and Sami Shousha.

Further details: Sandra Lock, Department of Histopathology, Hammersmith Hospital, Du Cane Road, London W12 0NN, UK. Tel: +44 (0)20 8383 3292; Fax: +44 (0)20 8740 7417; Email:histopathology.shortcourses@imperial. ac.uk

\section{CORRECTION}

doi: 10.1136/jcp.2006.032300.corr l

The citations of figures 3 and 4 in the article by Johnston (Johnston SL. Biologic therapies: what and when? J Clin Pathol 2007;60:8-17.) should have been transposed. The citation for figure 3 should appear on page 9 and the citation for figure 4 on page 10 . 